\title{
SOSIALISASI ADMINISTRASI PEMERINTAHAN DESA BAGI MAHASISWA KKN UNIVERSITAS SANG BUMI RUWA JURAI
}

\author{
Lies Kumara Dewi ${ }^{*}$, Novalia ${ }^{2,}$ Eka Ubaya Taruna rauf ${ }^{3}$, Henni Kusumastuti ${ }^{4}$ \\ 1,2,3,4 Universitas Sang Bumi Ruwa Jurai \\ e-mail: 1*lieskumaradewi13@gmail.com, ${ }^{2}$ novaliasholehah@gmail.com, ${ }^{3}$ ekaubaya77@gmail.com, \\ ${ }^{4}$ hennirek19@gmail.com
}

\begin{abstract}
Abstrak
Kiprah mahasiswa bersama-sama dengan masyarakat diharapkan mampu membangun desa dengan menggerakkan semua potensi yang dimiliki baik potensi alam, manusia, maupun potensi teknologi. Mahasiswa Kuliah Kerja Nyata (KKN) tidak semuanya memahami mengenai administrasi pemerintahan desa, oleh karena itu sebelum KKN mahasiswa perlu dibekali ilmu mengenai Administrasi Pemerintahan Desa. Adapun tujuan mengadakan sosialisasi ini adalah agar mahasiswa mengetahui administrasi pemerintahan desa sehingga kelak dapat membantu pemerintah desa dalam menyelenggarakan administrasi desa yang lebih tertib dan rapi berbasis teknologi. Khalayak sasaran dari kegiatan pengabdian kepada masyarakat ini yaitu mahasiswa KKN Universitas Sang Bumi Ruwa Jurai Tahun 2019 yang berjumlah 178 mahasiswa. Metode pelaksanaan pengabdian ini melalui empat tahapan yaitu tahap persiapan, pelaksanaan, monitoring dan evaluasi. Pelaksanaan kegiatan sosialisasi administrasi pemerintahan desa bagi mahasiswa KKN dilaksanakan pada hari sabtu, 26 Januari 2019 di Gedung Graha Saburai, Universitas Sang Bumi Ruwa Jurai Bandar Lampung. Setelah mengikuti sosialisasi, pemahaman peserta mengenai administrasi pemerintahan desa meningkat. Hal tersebut terlihat dari rata-rata pemahaman peserta mengenai administrasi pemerintahan desa setelah mengikuti sosialisasi sebesar 79,75. Selain peningkatan pemahaman mengenai administrasi pemerintahan desa, peserta juga memperoleh pengetahuan mengenai beberapa aplikasi yang ada mengenai administrasi pemerintahan desa.
\end{abstract}

Kata kunci: Administrasi, Mahasiswa KKN, Pemerintah Desa, Sosialisasi

\begin{abstract}
Students' work together with the community is expected to be able to build villages by mobilizing all the potential they have, both natural, human, and technological potential. Not all of the Real Work Lecture (KKN) students understand village government administration, therefore before KKN students need to be equipped with knowledge about Village Government Administration. The purpose of holding this socialization is so that students know the administration of village government so that later they can assist the village government in organizing a more orderly and technology-based village administration. The target audience of this community service activity is the 2019 Sang Bumi Ruwa Jurai University KKN students, totaling 178 students. The method of implementing this service goes through four stages, namely the preparation, implementation, monitoring and evaluation stages. The implementation of village government administration socialization activities for KKN students was carried out on Saturday, January 26, 2019 at the Graha Saburai Building, Sang Bumi Ruwa Jurai University, Bandar Lampung. After participating in the socialization, participants' understanding of village government administration increased. This can be seen from the average understanding of participants regarding village government administration after participating in the socialization of 79.75. In addition to increasing understanding of village government administration, participants also gained knowledge about several existing applications regarding village government administration.
\end{abstract}

Keywords: Administration, KKN Students, Village Government, Socialization

1. PENDAHULUAN
Kegiatan Kuliah Kerja Nyata (KKN)

mulai dilaksanakan sejak tahun akademik 
1971/1972, disebut dengan pengabdian mahasiswa kepada masyarakat. Kegiatan pengabdian kepada masyarakat ini lebih ditingkatkan setelah presiden Republik Indonesia pada bulan Februari 1972, yang menganjurkan dan mendorong setiap mahasiswa bekerja di desa dalam jangka waktu tertentu untuk tinggal dan membantu masyarakat pedesaan memecahkan masalah pembangunan sebagai bagian dari kurikulumnya [1]. Seperti yang telah di tetapkan, bahwa kegiatan KKN ini menjadi kewajiban yang ditetapkan Direktorat Jenderal Pendidikan Tinggi di Indonesia, yang menyatakan setiap Perguruan Tinggi untuk dapat melaksanakan KKN sebagai kegiatan intrakulikuler yang memadukan aspek Tri Dharma Perguruan Tinggi, yakni Pendidikan, Penelitian, dan pengabdian kepada masyarakat [2]. Dasar kebijakan Kuliah Kerja Nyata tersebut yaitu Undang-undang Nomor 20 Tahun 2003, tentang system pendidikan nasional, Undang- undang Nomor 12 tahun 2012 tentang perguruan tinggi dan sebagainya [3].

Universitas Sang Bumi Ruwa Jurai sebagai salah satu Perguruan Tinggi di Provinsi Lampung mewajibkan mahasiswa untuk mengikuti program KKN sebagai bentuk salah satu tri dharma perguruan tinggi yaitu pengabdian kepada masyarakat. Program KKN Universitas Sang Bumi Ruwa Jurai biasanya dilaksanakan di Desa-Desa yang ada di Provinsi Lampung. Mahasiswa yang mengikuti program KKN berasal dari empat fakultas yaitu Fakultas
Hukum, Fakultas Ekonomi, Fakultas Ilmu Sosial dan Ilmu Politik, dan Fakultas Teknik.

Kiprah mahasiswa secara langsung bersama-sama masyarakat mengidentifikasi potensi dan menangani masalah sehingga diharapkan mampu mengembangkan potensi desa/daerah dan meramu solusi untuk masalah yang ada di desa [4] baik potensi alam (natural resources), manusia (human resources), maupun potensi teknologi (technological resources). Kemampuan perangkat desa dan pemuda dalam hal manajemen administrasi desa belum menunjukkan ketertiban administrasi yang sesuai dengan standar operasional pelak- sanaan. Permasalahan yang terjadi manajemen administrasi desa masih belum tersusun dengan rapi [5].

Administrasi Pemerintahan Desa dapat berjalan degan baik apabilah kualitas sumber daya manusia yang melaksanakan dan menerapkan administrasi Desa handal dan memiliki kemampuan dalam menjalankan tugas yang diberikan. Kemajuan dari suatu Desa ditentukan dengan kapasitas dan kapabilitas dari para pelaku dalam tata kelolah administrasi yang diterapkan namun disamping sumber daya manusia yang baik harus juga dibaringi dengan efisien dan efektifnya penataan yang dilakukan sehingga dalam teknis penyelenggaraanya tidak akan mendapatkan masalah [6].

Dalam penyelengaraan administrasi desa berpedoman pada Permendagri No. 47 Tahun 2016 tentang Administrasi Pemerintahan Desa. 
Adapun Administrasi Pemerintahan Desa adalah keseluruhan proses kegiatan pencatatan data dan informasi mengenai Pemerintahan Desa. Administrasi pemerintahan desa adalah adalah keseluruhan proses kegiatan pencatatan data dan informasi mengenai Pemerintahan Desa pada Buku Register Desa [7]. Jenis-jenis administrasi pemerintahan desa meliputi administrasi umum, administrasi penduduk, administrasi keuangan, administrasi pembangunan dan Permusyawaratan Desa [8].

Untuk meningkatkan manajemen Pemerintahan Desa perlu dilakukan penataan administrasi agar lebih efektif dan efisien [9], penataan administrasi merupakan pencatatan data dan informasi dalam mendukung penyelenggaraan Pemerintahan Desa, maka perlu dilakukan langkah penyempurnaan terhadap pelaksanaan administrasi [10]. Tujuan dibuatkan administrasi desa yang tertib dan akurat adalah sebagai Pedoman bagi aparat Pemerintah Desa dalam melakukan kegiatan pencatatan penyelenggaraan Pemerintahan Desa.

Pengabdian sejenis sudah pernah dilakukan oleh beberapa pengabdi, antara lain peningkatkan kapasitas aparatur dan masyarakat desa tentang administrasi pemerintahan desa dan mendorong tertib administrasi pelayanan desa pada Desa Nansean Kecamatan Insana Kabupaten Timor Tengah Utara [11]. pemberian pengetahuan yang memadai mengenai administrasi desa dan memberikan pelatihan berbasis komputer tentang administrasi desa kepada perangkat desa [12]. Selanjutnya pernah diadakan penataan administrasi pemerintahan desa yang baik dan benar oleh aparatur pemerintah desa [13]. Dari beberapa pengabdian sebelumnya, belum pernah diadakan sosialisasi mengenai administrasi pemerintah desa kepada mahasiswa. Padahal salah satu kegiatan mahasiswa adalah KKN yang mewajibkan mahasiswa untuk terjun langsung mengabdi di tengah-tengah masyarakat. Hal inilah yang dijadikan unsur kebaruan dari tim pengabdi pada kegiatan ini.

Mahasiswa KKN tidak semuanya memahami mengenai administrasi pemerintahan desa. Oleh karena itu sebelum diberangkatkan, mahasiswa perlu dibekali ilmu mengenai Administrasi Pemerintahan Desa. Sehingga, tujuan mengadakan sosialisasi ini adalah agar mahasiswa mengetahui administrasi pemerintahan desa sehingga kelak dapat membantu pemerintah desa dalam menyelenggarakan administrasi desa yang lebih tertib dan rapi berbasis teknologi.

\section{METODE}

\subsection{Khalayak Sasaran}

Khalayak sasaran dari kegiatan pengabdian kepada masyarakat ini yaitu mahasiswa KKN Universitas Sang Bumi Ruwa Jurai Tahun 2019 yang berjumlah 178 mahasiswa. Mahasiswa berasal dari empat Fakultas yaitu Fakultas Ekonomi, Fakultas 
Hukum, Fakultas Ilmu Sosial dan Ilmu Politik serta Fakultas Teknik.

\subsection{Metode Pelaksanaan}

Metode pelaksanaan pengabdian ini melalui empat tahapan yaitu tahap persiapan, pelaksanaan, monitoring dan evaluasi. Pelaksanaan kegiatan sosialisasi administrasi pemerintahan desa bagi mahasiswa KKN dilaksanakan pada hari sabtu, 26 Januari 2019 di Gedung Graha Saburai, Universitas Sang Bumi Ruwa Jurai Bandar Lampung.

Pada tahap pertama yaitu tahap persiapan, pengabdi mengkondisikan peserta agar siap mengikuti sosialisasi serta memberikan pre test untuk mengetahui kemampuan awal peserta mengenai administrasi pemerintahan desa. Tahap kedua yaitu tahap pelaksanaan, pengabdi mensosialisasikan materi mengenai administrasi pemerintahan desa serta memperlihatkan contoh aplikasi-aplikasi administrasi desa. Penyampaian materi diharapkan mampu peningkatkan pemahaman mahasiswa mengenai administrasi pemerintahan desa.

Tahap ketiga yaitu tahap monitoring, tim pengabdi lainnya yang tidak menyampaikan materi memonitor peserta yang mengikuti sosialisasi. Peserta harus memperhatikan pemateri agar mengerti materi yang disampaikan pemateri. Tahap Keempat yaitu tahap evaluasi, pada tahap ini peserta diwajibkan mengisi pos test. Selain post test peserta juga mengisi kuesioner mengenai materi dan pemateri yang penyampaikannya. Diagram alir metode pelaksanaan pengabdian kepada masyarakat dapat dilihat pada Gambar 1.

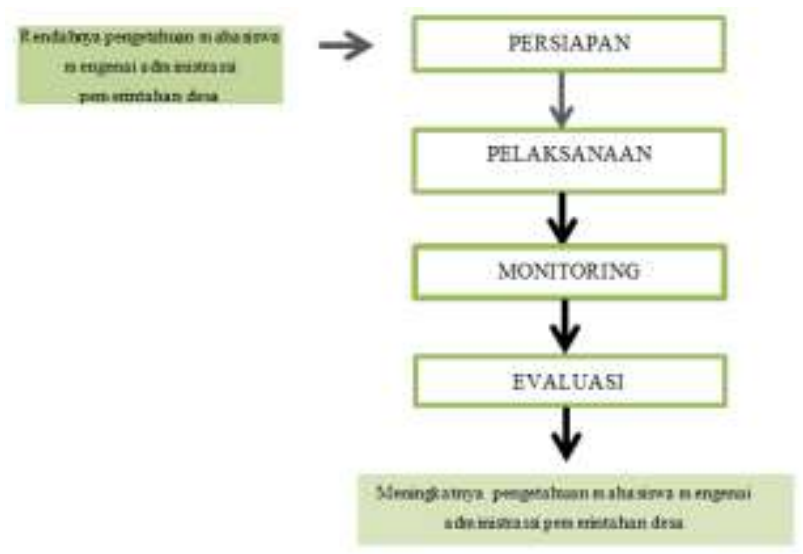

Gambar 1. Metode Pelaksanaan PkM

\section{HASIL DAN PEMBAHASAN}

Pelaksanaan kegiatan pengabdian diawali dengan memberikan pre-test mengenai administrasi pemerintahan desa. Hal ini dilakukan untuk mengetahui kemampuan awal peserta. Berdasarkan hasil pre-test, diperoleh hasil mengenai pemahaman peserta tentang administrasi pemerintahan seperti yang terlihat pada Gambar 2.

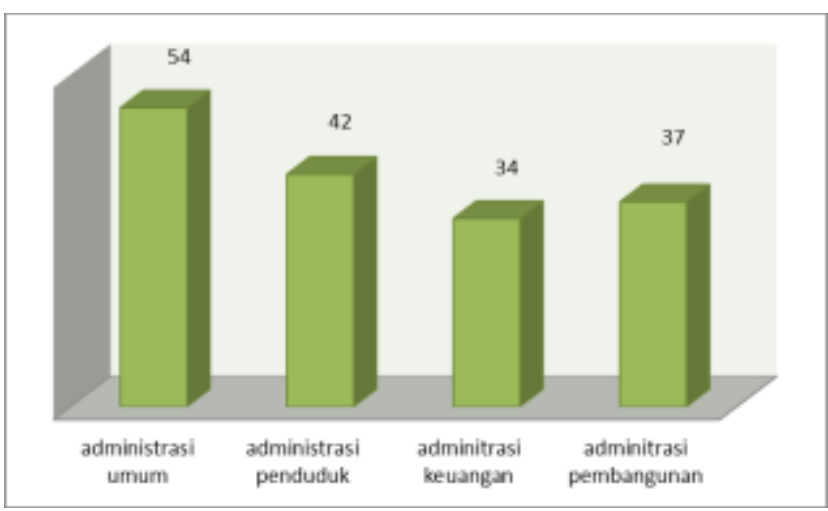

Gambar 2. Grafik Rata-Rata Kemampuan Awal Peserta mengenai Administrasi Pemerintahan Desa 
Berdasarkan Gambar 2, rata-rata kemampuan awal peserta mengenai administrasi umum sebesar 54, administrasi penduduk sebesar 42, administrasi keuangan sebesar 34 dan administrasi pembangunan sebesar 37. Rata-rata kemampuan awal peserta mengenai ke empat administrasi tersebut masih di bawah 50 hanya kemampuan awal mengenai administrasi umum yang di atas 50. Rata-rata kemampuan awal peserta mengenai administrasi pemerintahan desa yaitu 41,75 , nilai ini masih di bawah 50 .

Setelah melakukan pre-test, selanjutnya Pemateri menjelaskan mengenai administrasi pemerintahan desa mulai dari pengertian administrasi, pemerintahan desa dan macammacam administrasi yang ada pada pemerintahan desa. Setelah sosialisasi administrasi pemerintahan desa, dilakukan diskusi dengan peserta agar peserta benar-benar memahami materi administrasi pemerintahan desa. Untuk mengetahui pemahaman peserta mengenai administrasi pemerintahan desa setelah dilakukan sosialisasi. Pemahaman peserta mengenai administrasi pemerintahan desa setelah dilakukan sosialisasi dapat dilihat pada Gambar 3.

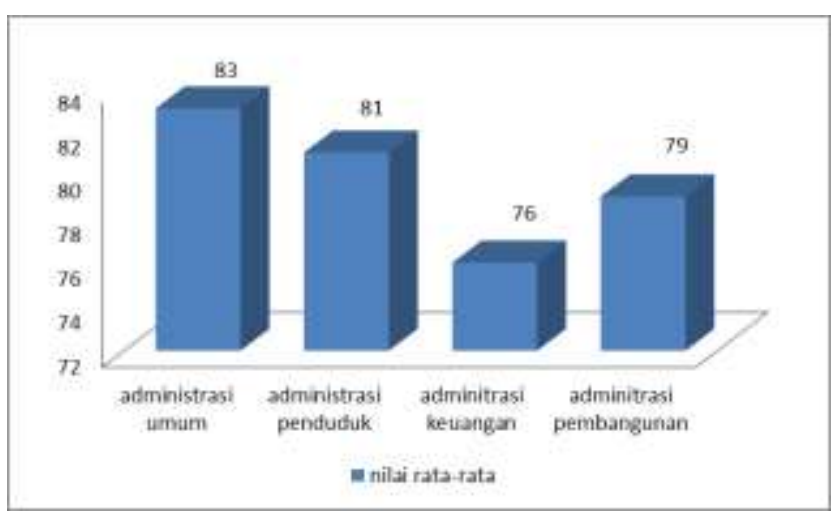

Gambar 3. Pemahaman Peserta Mengenai Administrasi Pemerintahan Desa Setelah Mengikuti Sosialisasi

Berdasarkan Gambar 3. terlihat bahwa pemahaman peserta mengenai administrasi pemerintahan desa setelah mengikuti sosialisasi meningkat. Rata-rata pemahaman peserta setelah mengikuti sosialisasi mengenai administrasi umum sebesar 83, administrasi penduduk sebesar 81, administrasi keuangan sebesar 76 dan administrasi pembangunan sebesar 79 . Rata-rata pemahaman peserta mengenai administrasi pemerintahan desa setelah mengikuti sosialisasi sebesar 79,75. Nilai ini lebih besar dari rata-rata kemampuan awal peserta. Peningkatan pemahaman peserta sebelum dan sesudah mengikuti sosialisasi dapat dilihat pada Gambar 4.

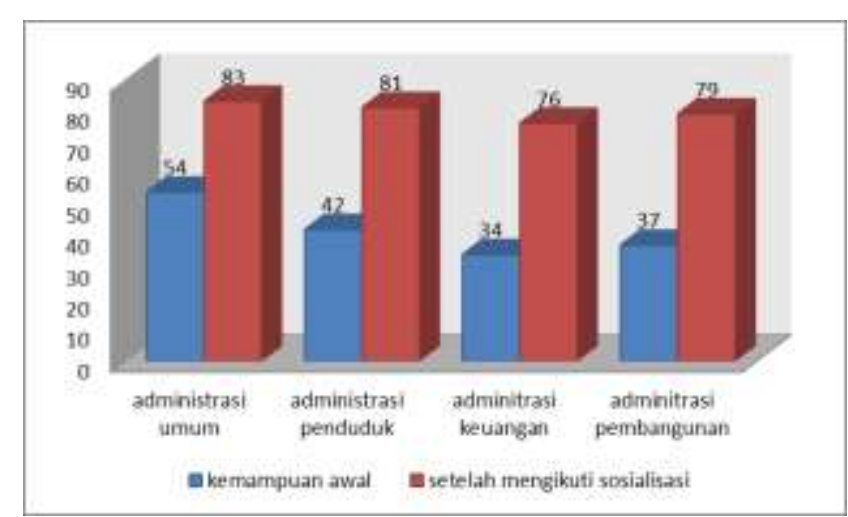

Gambar 4. Peningkatan Pemahaman Peserta 
Sebelum dan Sesudah mengikuti Sosialisasi Administrasi Pemerintahan Desa

Selain peningkatan pemahaman mengenai administrasi pemerintahan desa, peserta juga diberikan pengetahuan mengenai beberapa aplikasi yang ada mengenai administrasi pemerintahan desa. Diharapkan dengan mengetahui aplikasi administrasi pemerintahan desa, peserta kelak bisa memperbaiki administrasi desa yang menjadi objek KKN dan membuat aplikasi administrai desa. Contoh aplikasi administrassi pemerintahan desa dapat dilihat pada Gambar 5.

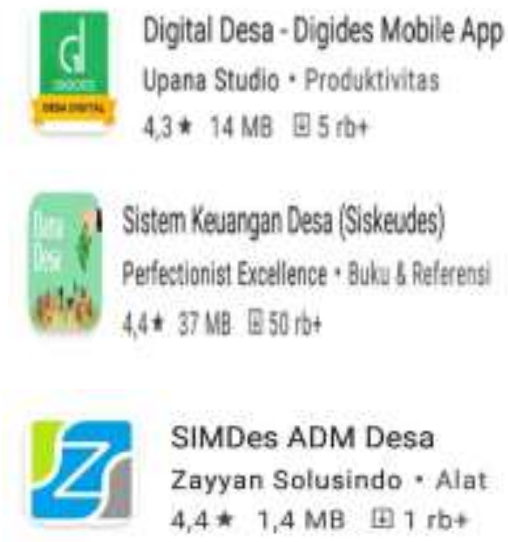

Gambar 5. Tiga Contoh Aplikasi Administrasi Pemerintahan Desa

\section{SIMPULAN}

Setelah melakukan kegiatan sosialisasi administrasi pemerintahan desa disimpulkan bahwa Rata-rata kemampuan awal peserta mengenai administrasi pemerintahan desa yaitu 41,75, masih di bawah 50. Setelah dilakukan sosialisasi, Pemahaman peserta mengenai administrasi pemerintahan desa setelah mengikuti sosialisasi meningkat. Rata-rata pemahaman peserta mengenai administrasi pemerintahan desa setelah mengikuti sosialisasi naik menjadi 79,75. Kelebihan dari kegiatan pengabdian kepada masyarakat ini yaitu materi yang disampaikan benar-benar dibutuhkan peserta yang hendak melaksanakan $\mathrm{KKN}$ dan pemateri sesuai dengan bidang ilmunya, sedangkan kekurangannya yaitu waktu yang tersedia kurang sehingga untuk aplikasi adminitrasi desa hanya sebatas pengenalan.

\section{SARAN}

Kegiatan pengabdian selanjutkan fokus ke salah satu jenis administrasi pemerintahan, contoh administrasi kependudukan serta waktunya diperpanjang sehingga memungkinkan untuk contoh penggunaan beberapa aplikasi administrasi pemerintahan desa.

\section{UCAPAN TERIMA KASIH}

Penulis mengucapkan terima kasih kepada pihak panitia KKN Universitas Sang Bumi Ruwa Jurai yang telah mempercayakan penulis untuk menjadi pemateri dan peserta yang antusias mengikuti kegiatan sosialisasi administrasi pemerintahan desa ini. 


\section{DAFTAR PUSTAKA}

[1] A. Marjuni, M. Rusli, and M. Maryam, Sedekah Cinta sang Pengabdi Masyarakat. Makassar: Pusaka Almaida, 2017.

[2] D. S. Djamdjuri and G. C. K. P. Prasetya, "Memperkenalkan Cara Pengaplikasian Komputer Terhadap Anak Sekolah Dasar (Ciampea Udik, Caringin Jangkung)," Abdi Dosen J. Pengabdi. Pada Masy., vol. 4, no. 2, pp. 146-151, 2020, doi: 10.32832/abdidos.v4i2.584.

[3] M. I. Efendi et al., "Pemberdayaan Masyarakat Jelehan Kulon dalam Konsep Masyarakat Belajar dan Penanaman Nilai Karakter," Pros. Konf. Pengabdi. Masy., vol. 1, no. Maret, pp. 413-420, 2019, [Online].

Available:

http://sunankalijaga.org/prosiding/index.ph p/abdimas/article/download/332/307.

[4] M. Mudzakir, "Determinan Merdeka Belajar Kampus Merdeka Terhadap Minat Belajar Mahasiswa Universitas Pamulang," HUMANIS (Humanities, Manag. Sci. Proceedings), vol. 1, no. 2, pp. 644-661, 2021.

[5] A. Hariyadi, M. Hawa, S. Sutrimah, S. A. Sofwani, and E. Yuliani, "Pelatihan Manajemen Pengelolaan Administrasi Menggunakan Metode Demonstrasi Di Wotsogo Jatirogo Tuban," InEJ Indones. Engagem. J., vol. 1, no. 2, pp. 181-187, 2020, doi: 10.21154/inej.v1i2.2333.
[6] S. S. Sondakh, M. Kimbal, and J. Kairupan, "Implementasi Administrasi Pemerintah Desa dalam Menunjang Pembangunan di Desa Kanonang Dua Kecamatan Kawangkoan Barat Kabupaten Minahasa," J. Eksek., vol. 1, no. 1, 2017.

[7] Sotya Partiwi Ediwijoyo, Wakhid Yuliyanto, and Ari Waluyo, "Meningkatkan pelayanan publik Di Desa Padureso Kec. Padureso Kebumen dengan Sosialisasi dan PenyuluhanTata Kelola Administrasi Desa," JURPIKAT (Jurnal Pengabdi. Kpd. Masyarakat), vol. 1, no. 3, pp. 2020, doi: 10.37339/jurpikat.v1i3.412.

[8] S. S. Hutagalung, N. Mulyana, and D. Hermawan, "Peningkatan Kualitas Pelayanan Publik Bagi Layanan Administrasi Pemerintahan Desa kecamatan Jati Agung Kabupaten Lampung Selatan," Sakai Sambaian J. Pengabdi. Kpd. Masy., vol. 1, no. 2, pp. 54-60, 2017.

[9] R. Yulida, R. Rosnita, D. Kurnia, Y. Andriani, and F. Septya, "Pembuatan dan Pelatihan Website Administrasi Desa Bukit Lingkar Kecamatan Batang Cenaku Kabupaten Indragiri Hulu, PengabdianMu J. Ilm. Pengabdi. Kpd. Masy., vol. 6, no. 2, pp. 164-169, 2021, doi: 10.33084/pengabdianmu.v6i2.1677.

[10] R. Purbowati and M. Astutik, "Pelatihan Microsoft Office Sebagai Upaya 
Peningkatan Kemampuan Aparat Desa

Dalam Pelaksanaan Tugas Administrasi

Pemerintahan Desa," Comvice J.

community Serv., vol. 1, no. 1, pp. 1-8, 2017, doi: 10.26533/comvice.v1i1.115.

[11] handrianus V. M. Wula, E. Kalembang, and M. Suni, "Pelatihan administrasi pemerintahan sebagai upaya peningkatan kapasitas aparatur pemerintahan desa dan masyarakat di desa nansean," bakti Cendana, vol. 3, no. 2, pp. 112-117, 2020.

[12] O. Onsardi, A. Sumarlan, and $M$. Finthariasari, "Tata Kelola Adminitrasi Desa Tepi Laut Kecamatan Air Napal Kabupaten Bengkulu Utara," J. Pengabdi. Masy. Bumi Raflesia, vol. 2, no. 1, pp. 7580, 2019, doi: 10.36085/jpmbr.v2i1.288.

[13] M. Alkadafi, Rusdi, and M. April, "Penataan Administrasi Pemerintahan Desa Di Desa Kualu Nenas Kecamatan Tambang Kabupaten Kampar," Din. J. Pengabdi. Kpd. Masy., vol. 3, no. Special Issue, pp. 76-84, 2019, doi: 10.31849/dinamisia.v3i2.2865. 